\title{
KETAHANAN MEMBRAN KOMPOSIT KITOSAN/ POLISULFON TERHADAP pH
}

\author{
Maria Erna, Sri Haryati, Roy Naldo ${ }^{1}$ dan Yeni Fitri Yana ${ }^{2}$ \\ ${ }^{1}$ Program Studi Pendidikan Kimia FKIP Universitas Riau \\ Kampus Binawidya km 12 Pekanbaru \\ ${ }^{2}$ SMAN 1 Bangko, Jl. Gedung Nasional Bagan Siapiapi Rokan Hilir Provinsi Riau \\ email : bun_erna@yahoo.com
}

\begin{abstract}
It has been done resistance test of chitosan/polysulfon composite membrane to solvent. The results of research obtained that resistance composite membrane to $\mathrm{pH}$. This matter is marked with its percentage swelling highest that is $75.48 \%$. This result is also supported by porous photo membrane using SEM that is across-section, up surface and bottom photo showed that happed change porous structure membrane but structure tying membrane can not experiencing of damage.
\end{abstract}

Keywords: composite membrane, chitosan, percentage of swelling

\section{PENDAHULUAN}

Membran didefinisikan suatu lapisan tipis semipermeabel yang berada di antara dua fasa. Teknologi membran banyak digunakan dalam industri sebagai alternatif dari teknologi pemisahan konvensional seperti penyulingan, ekstraksi dan kromatografi. Sifat spesifik membran sangat dipengaruhi jenis polimer dan teknik pembuatannya.

Pada penelitian ini membran dibuat dengan bahan baku polisulfon dan kitosan yang dikompositkan melalui metode inverse fasa dan pencelupan. Dari penelitian ${ }^{[1]}$ membran komposit yang mempunyai kombinasi fluks dan koefisien rejeksi yang terbaik pada perbandingan membran pendukung 18:64:18 dan perbandingan kitosan dengan pelarutnya $1: 10 \mathrm{w} / \mathrm{v}$.

Kitosan dipilih karena termasuk biopolimer hidrofilik alami dan tahan terhadap pelarut, disamping itu kitosan mudah didapat di alam yang merupakan hasil reaksi deasetilasi kitin dan larut dalam asam asetat ${ }^{[2]}$. Sedangkan polisulfon dipilih karena polimer jenis ini mempunyai kualitas mekanis dan kestabilan kimia yang cukup baik serta memiliki pori-pori yang relatif besar sehingga fluksnya untuk sementara baik ${ }^{[3]}$.
Untuk mendapatkan sifat spesifik membran komposit polisulfon/kitosan terhadap $\mathrm{pH}$, perlu dilakukan penelitian untuk menguji ketahanannya. Pada penelitian ini ketahanan membran komposit ditentukan dengan mengukur persen swelling setelah membran direndam selama 24 jam dalam akuades yang diatur pHnya. Sedangkan range $\mathrm{pH}$ larutan akuades digunakan dari 2,5-12. Morfologi pori-pori membran dipelajari dengan menggunakan Scanning Electron Microscopy (SEM).

\section{METODOLOGI}

Bahan yang digunakan sebagai berikut kitin dari limbah udang, $\mathrm{NaOH}$, Polisulfon (PSf), Polietilenglikol (PEG), N,N-dimetilasetamida (DMAc)-Merck, asam asetat-Merck, dan $\mathrm{HCl}$ (Merck).

\section{Pemisahan Kitin Dari Limbah Udang}

Limbah cangkang udang dibersihkan dengan cara dicuci, kemudian dikeringkan dalam oven selama 5 jam pada suhu $70-75^{\circ} \mathrm{C}$. Cangkang udang yang telah kering diblender hingga menjadi serbuk dan dimasukkan ke dalam gelas piala dan ditambahkan $\mathrm{NaOH} 1 \mathrm{~N}$, kemudian dipanaskan pada suhu $80^{\circ} \mathrm{C}$ selama 3 jam sambil diaduk. Campuran disaring dan 
dicuci serta dimasukkan kembali ke dalam gelas piala, lalu ditambahkan $\mathrm{HCl} 1 \mathrm{~N}$ dan dibiarkan selama 12 jam pada suhu kamar. Perlakuan $\mathrm{NaOH}$ dan $\mathrm{HCl}$ diulang sebanyak dua kali, setelah itu padatan kitin yang diperoleh direfluks dengan aseton hingga terbentuk butiran-butiran putih ${ }^{[4]}$.

\section{Perubahan Kitin Menjadi Kitosan (Proses Deasetilasi)}

Kitin sebanyak $20 \mathrm{~g}$ ditambahkan $200 \mathrm{~mL}$ $\mathrm{NaOH} 47 \%$ dan dipanaskan pada suhu $110^{\circ} \mathrm{C}$ selama 4 jam, kemudian dilakukan penyaringan, pencucian dan pengeringan. Padatan kitosan siap digunakan sebagai bahan baku pembuatan membran komposit ${ }^{[4]}$.

\section{Pembuatan Membran Komposit Kitosan/Polisulfon}

Polisulfon (PSf) dilarutkan dalam DMAc dan ditambahkan PEG, dengan perbandingan berat 18:64:18 dan diaduk dengan pengaduk magnet selama 10 - 20 jam dalam erlenmeyer tertutup, lalu didiamkan antara $3-4$ jam untuk menghilangkan gelembung udara. Disiapkan alat pencetak membran, yaitu kaca yang telah dilapisi selotip di sisi kiri dan kanannya, dihamparkan pada meja horizontal, sementara itu bak koagulasi diisi dengan air. Kemudian larutan dituangkan di atas kaca dan diratakan dengan batang silinder stainless steel hingga terbentuk lapisan tipis, kemudian kaca direndam ke dalam bak koagulasi. Membran yang sudah terkoagulasi kemudian dicuci berulang-ulang dengan air mengalir untuk menghilangkan sisa pelarutnya ${ }^{[5]}$.

Kemudian kitosan dilarutkan dalam asam asetat dengan variasi perbandingan 1: $10(\mathrm{w} / \mathrm{v})$, kemudian disaring dan hasil larutan siap dilapisi pada permukaan atas membran polisulfon dengan cara pencelupan selama 30 menit, kemudian dibiarkan dan dikeringkan pada temperatur ruang dan selanjutnya membran dikeringkan pada temperatur $70^{\circ} \mathrm{C}$ selama 2 jam di dalam oven. Kemudian membran ditambahkan $\mathrm{NaOH} 2,6 \%$ dalam metanol, lalu dicuci dengan air serta dikeringkan. Membran komposit kitosanpolisulfon siap untuk diuji ketahanan terhadap pelarut, $\mathrm{pH}$ dan ditentukan waktu operasi serta dikarakterisasi.

\section{Uji Ketahanan Membran Komposit Terhadap pH}

Membran komposit ditimbang beratnya dan langsung dikontakkan secara statis dengan larutan dengan $\mathrm{pH}(2,5 ; 4,0 ; 5,5 ; 7,0 ; 8,5 ; 10,0$ dan 11,5) diatur dengan menggunakan $2 \mathrm{~N} \mathrm{HCl}$ atau $\mathrm{NaOH}$ dan dibiarkan selama 24 jam pada temperatur $25^{\circ} \mathrm{C}$. Lalu membran dikeringkan di dalam oven selama 24 jam pada temperatur $40^{\circ} \mathrm{C}$. Selanjutnya persentase swelling dihitung.

\section{Penentuan Morfologi Membran}

Membran yang mempunyai persentase swelling yang paling rendah dan tinggi baik terhadap pelarut maupun terhadap $\mathrm{pH}$, poriporinya diamati dengan SEM dilanjutkan dengan pengambilan foto hasil pengamatan. Foto membran yang diambil adalah permukaan atas, bawah dan penampang lintang. Kemudian dianalisa bentuk dan ukuran pori-porinya.

\section{HASIL DAN PEMBAHASAN}

Rendemen kitin dari limbah udang diperoleh $27 \%$, sedangkan persentase kitosan yang dihasilkan 57\%. Jadi limbah udang ini berpotensi untuk dimanfaatkan sebagai bahan baku pembuatan membran, karena sumbernya sangat melimpah di alam, tidak toksik, biodegradasi, biocompatible, bioaktif dan bersifat polikationik.

Untuk mempelajari ketahanan membran komposit polisulfon/kitosan terhadap $\mathrm{pH}$ pada penelitian ini hanya melihat berapa besar persentase swelling (berapa besar kemampuan membran untuk mengadsorpsi pelarut tertentu yang dapat merubah stuktur pori-pori membran tersebut). Hal ini dilakukan karena persentase swelling dapat digunakan sebagai indikator ketahanan membran terhadap suatu pelarut. Semakin besar persentase swelling membran terhadap suatu pelarut maka semakin tahan membran untuk menahan pelarut tersebut ${ }^{[5]}$.

Dari hasil penelitian didapatkan persentase swelling membran yang paling tinggi terjadi pada $\mathrm{pH} 5,5(75,48 \%)$ dan paling rendah $\mathrm{pH}$ $11,5(15,6 \%)$ dapat dilihat pada Gambar 1. Hal ini disebabkan pada $\mathrm{pH} 5,5$ gugus amina kitosan mengalami protonasi dan bersifat 
hidrofilik. Gugus $\mathrm{H}^{+}$dari larutan akuades akan berikatan dengan gugus $\mathrm{NH}_{2}$ dari kitosan, sehingga larutan lebih banyak terperangkap dalam pori-pori membran. Sedangkan pada $\mathrm{pH}$ 11,5 gugus amina kitosan mengalami deprotonasi sehingga bersifat hidrofob. Menurut Rohindra bahwa persentase swelling dipengaruhi salah satunya oleh $\mathrm{pH}^{[6]}$.

Untuk foto membran yang direndam dengan pH 5,5 dapat diamati pada Gambar $2-4$. Dari hasil foto penampang lintangnya terlihat bahwa kitosan menutupi sebagian pori-pori sehingga mengurangi distribusi pori-pori pada permukaan atas maupun bawah. Sedangkan foto membran yang direndam dengan $\mathrm{pH}$ 11,5 dapat diamati pada Gambar $5-7$. Terlihat membran bersifat asimetrik, distribusi pori- pori terbuka pada permukaan atas dan bawah lebih banyak dari membran yang direndam dalam $\mathrm{pH}$ 5,5. Hal ini disebabkan kitosan membentuk gel di atas $\mathrm{pH} 7^{[7]}$.

\section{KESIMPULAN}

Dari hasil penelitian yang telah dilakukan sesuai dengan permasalahan serta tujuan penelitian maka dapat disimpulkan sebagai berikut bahwa membran komposit kitosan/polisulfon tahan terhadap $\mathrm{pH}$ larutan akuades 5,5 yang ditandai dengan persentase swellingnya paling tinggi yaitu $75,48 \%$ dan dari hasil foto SEM bahwa $\mathrm{pH}$ dapat merubah morfologi pori-pori membran komposit kitosan/polisulfon.

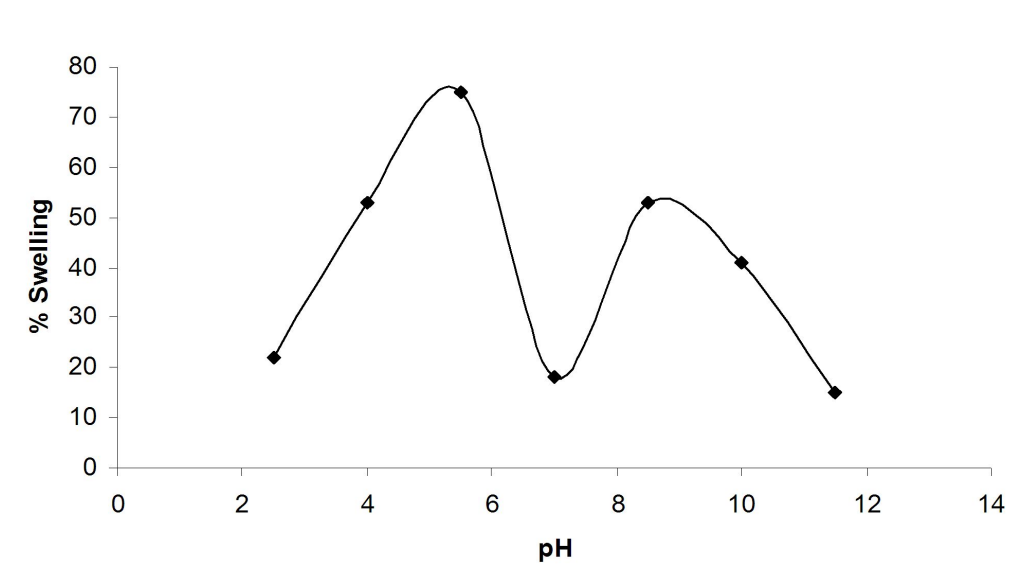

Gambar 1. Kurva persentase swelling membran terhadap $\mathrm{pH}$

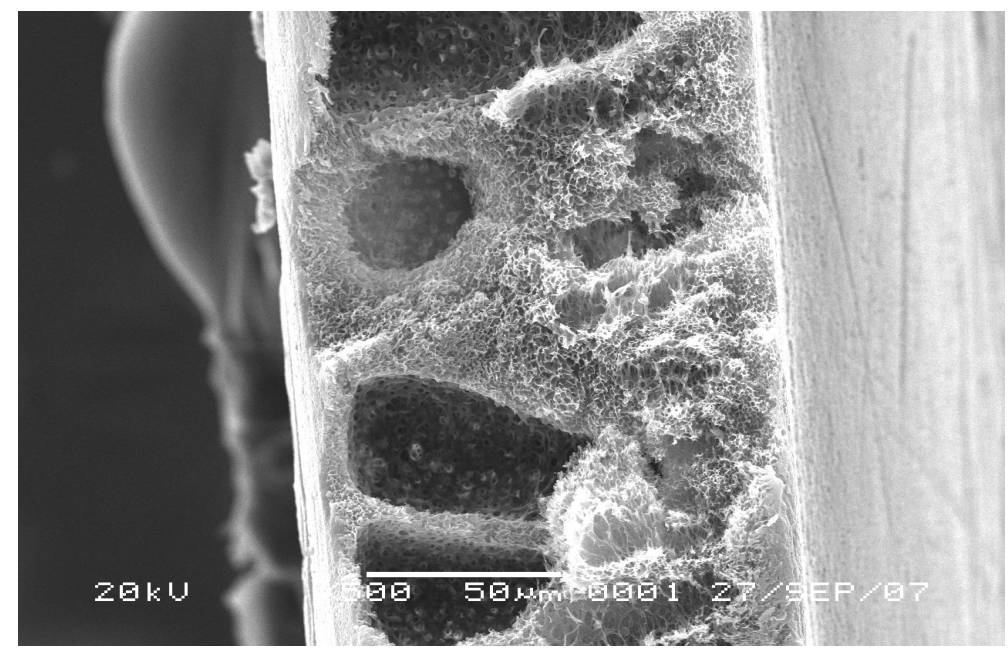

Gambar 2. Foto penampang membran pada $\mathrm{pH} 5,5$ 


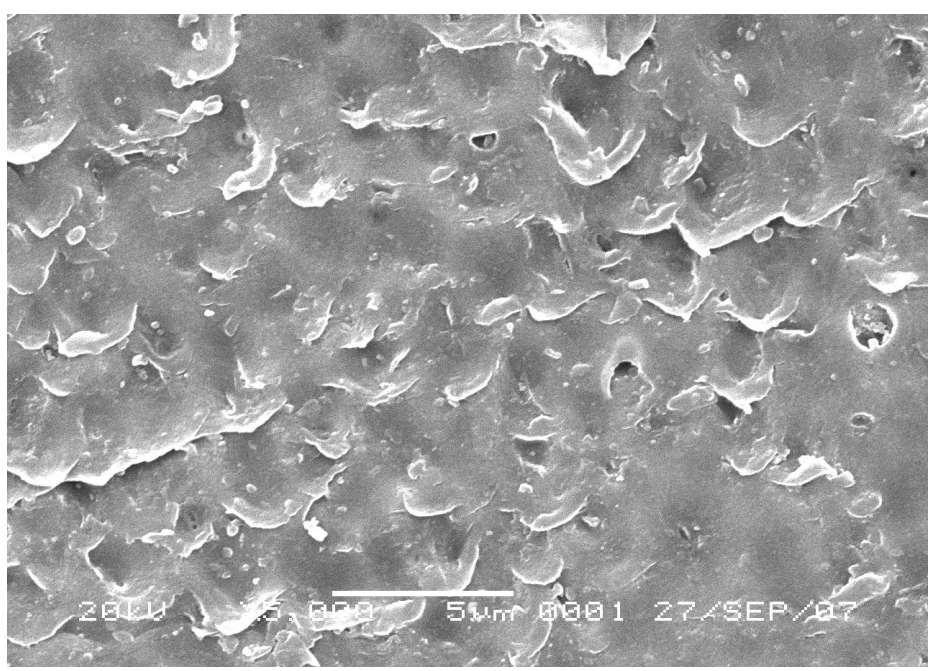

Gambar 3. Foto permukaan atas membran pada $\mathrm{pH} 5,5$

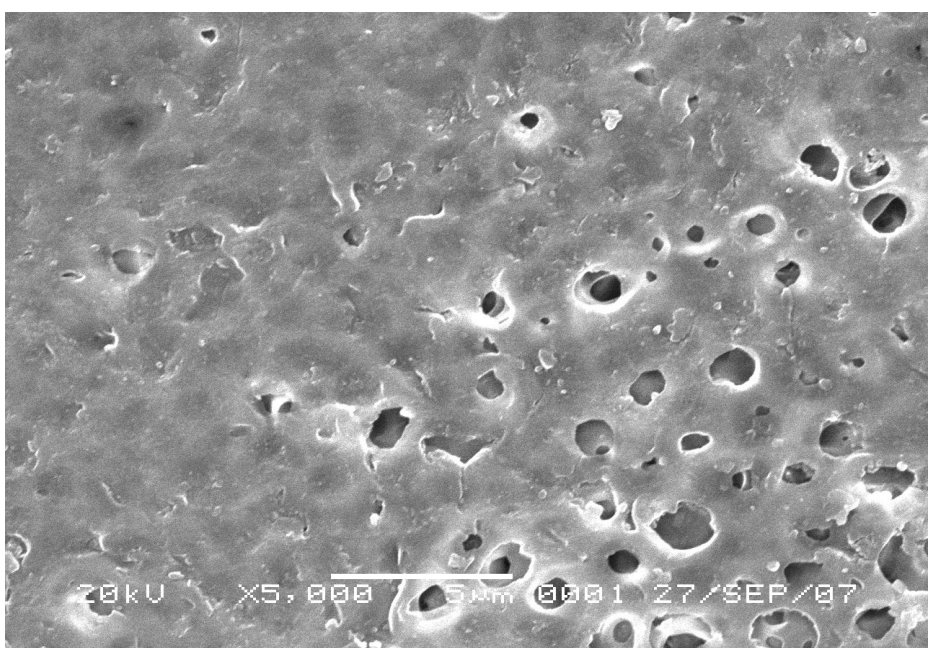

Gambar 4. Foto permukaan bawah membran pada $\mathrm{pH}$ 5,5

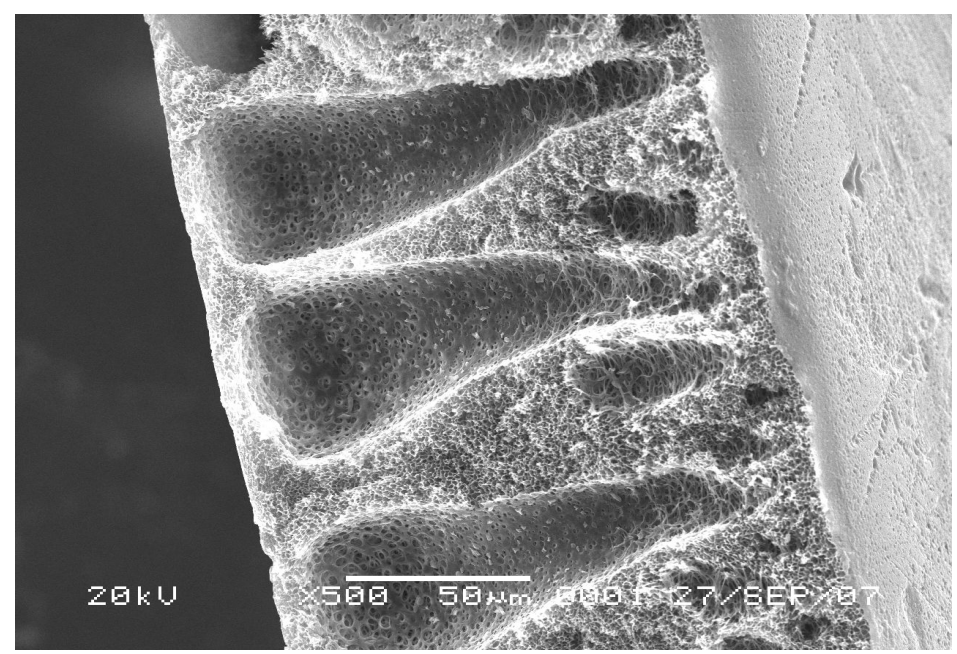

Gambar 5. Foto penampang membran pada $\mathrm{pH} 11,5$ 


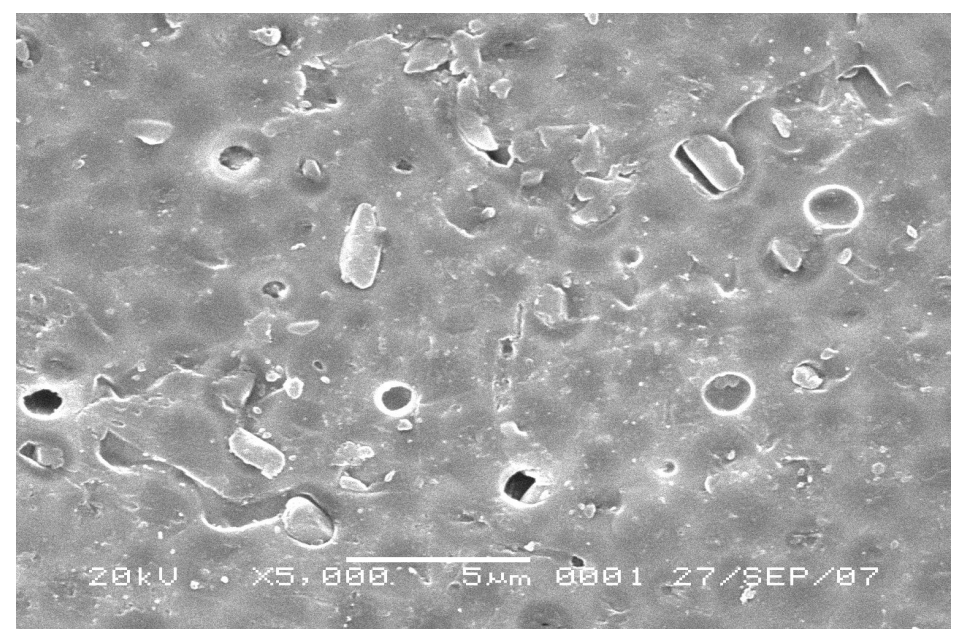

Gambar 6. Foto permukaan atas pada $\mathrm{pH} 11,5$

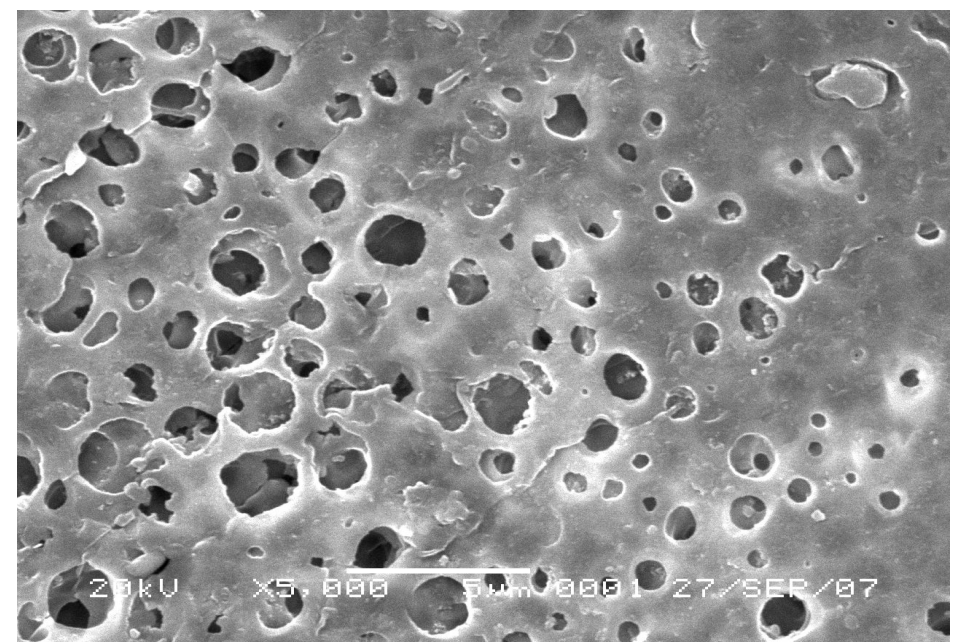

Gambar 7. Foto permukaan bawah pada $\mathrm{pH} 11,5$

\section{DAFTAR PUSTAKA}

1. M. Erna, \& Erman, Pembuatan dan karakterisasi membran komposit kitosan/polisulfon, Laporan penelitian Lemlit, Universitas Riau, 2004.

2. X. Feng, \& R. Y. Huang, Pervaporation with chitosan membranes. I. Separation of water from ethylene glycol by a chitosan/polysulfone composite membrane, J. Membran Science, 116: 67-76, (1996).

3. H. Pratomo, Membran komposit berpendukung untuk pemisahan zat warna tekstil secara proses osmosis balik, Tesis Magister Kimia, Institut Teknologi Bandung, 2000.
4. S. Mima, et al., Highly Deacetylated Chitosan and Its Properties, J. of Applied Polimer Sciences, 28: 1909-1917, (1983).

5. W. A. Muhammad, Satu sorotan mengenai teknik pembuatan dan jenis polimer untuk membran komposit penurasan nano. Universiti Kebangsaan Malaysia, 2001.

6. A. Kumar Musale \& A. Deepak, Solvent and $\mathrm{pH}$ Resistance of Surface Crosslinked Chitosan/Poly(acrylonitrile) Composite Nanofiltration Membranes, J. of Applied Polimer Sciences, 77: 1782-1793, (1999).

7. S. O. Fernandes-Kim, Physicochemical and Functional Properties of Crawfish Chitosan as Affected by Different Processing Protocols, Thesis, The department of Food Science, Seoul National University, (2004). 